\title{
DESKRIPSI SEKOLAH DASAR (SD) DI KABUPATEN MINAHASA TENGGARA BERDASARKAN STANDAR KOMPETENSI LULUSAN, STANDAR PROSES, STANDAR PEMBIAYAAN PENDIDIKAN DAN STANDAR PENILAIAN PENDIDIKAN
}

\author{
Rinny Tutud ${ }^{1)}$, Djoni Hatidja ${ }^{\left.1^{*}\right)}$, Hanny Komalig ${ }^{1)}$ \\ ${ }^{1)}$ Program Studi Matematika, FMIPA Universitas Sam Ratulangi, Manado \\ Coresponding author: dhatidja@gmail.com \\ email : rtutud@gmail.com; hanoy07@gmail.com
}

\begin{abstract}
ABSTRAK
Standar Nasional Pendidikan merupakan sistem pendidikan yang diterapkan di seluruh wilayah hukum Negara Kesatuan Republik Indonesia. Tujuan dari penelitian ini yaitu mendeskripsikan Sekolah Dasar di Kabupaten Minahasa Tenggara berdasarkan empat Standar Nasional Pendidikan yaitu Standar Kompetensi Lulusan, Standar Proses, Standar Pembiayaan Pendidikan dan Standar Penilaian Pendidikan. Penelitian ini dilakukan di Kabupaten Minahasa Tenggara, Sulawesi Utara pada bulan September 2017 dan sampel yang diambil yaitu 30 Sekolah Dasar (SD). Data yang digunakan adalah data primer berupa kuisioner. Teknik pengambilan sampel yakni Purposive Random Sampling yang digunakan untuk menentukan kecamatan yang akan dijadikan sampel, kemudian menggunakan Simple Random Sampling untuk menentukan sekolah-sekolah yang akan dijadikan sampel. Metode yang digunakan yaitu analisis deskripsi. SD GMIM Ratahan (K3) adalah sekolah yang memiliki nilai paling tinggi pada tiga Standar Nasional Pendidikan yaitu standar kompetensi lulusan, standar proses dan standar pembiayaan pendidikan, sekolah ini termasuk sekolah yang sudah terakreditasi A. Sedangkan sekolah yang memiliki nilai paling rendah adalah SD GMIM Kuyanga (K13) untuk standar kompetensi lulusan dan SD Negeri Kecil Banga (K17) untuk standar proses dan standar pembiayaan pendidikan, kedua sekolah tersebut termasuk sekolah yang belum terakreditasi. SD Negeri 1 Tombatu (K24) adalah sekolah yang memiliki nilai paling tinggi untuk standar penilaian pendidikan dan sekolah ini termasuk sekolah yang sudah terakreditasi. Sedangkan SD Negeri Wioi (K2) adalah sekolah dengan nilai paling rendah pada standar penilaian pendidikan dan sekolah ini termasuk sekolah yang sudah terakreditasi B.
\end{abstract}

Kata kunci : Sekolah Dasar (SD), Standar Nasional Pendidikan, Analisis Deskripsi, Kabupaten Minahasa Tenggara

\section{DESCRIPTION OF ELEMENTRY SCHOOL IN SOUTHEAST MINAHASA REGENCY BASED ON GRADUATES COMPETENCY STANDARD, PROCESS STANDARD, EDUCATION FINANCING STANDARD AND EDUCATION ASSESSMENT STANDARD}

\begin{abstract}
National Education Standard is an education system implemented throughout the jurisdiction of the Unitary State of the Republic of Indonesia. The purpose of this study is to describe the elementary school in Southeast Minahasa Regency based on four National Education Standard namely Graduates Competency Standard, Process Standard, Education Financing Standards and Education Assessment Standard. The research was conducted in Southeast Minahasa District, North Sulawesi in September 2017 and samples taken were 30 elementary schools. The data used is the primary data in the form of questionnaires. The sampling technique is Purposive Random Sampling which is used to determine the sub-district to be sampled, then using Simple Random Sampling to determine the schools that will be sampled. The method used is description analysis. GMIM Ratahan (K3) Elementry School is the school that has the highest score on the three National Education Standards namely graduate competency standards, process standards and
\end{abstract}


education financing standards, this school includes accredited schools A. While schools that have the lowest value are GMIM Kuyanga (K13) Elementry School for the competency standards of graduates and Negeri Banga (K17) Elementry School for standard process and education financing standards, both schools include unaccredited schools. Negeri 1 Tombatu (K24) Elementry School is the highest rated school for education and school assessment standards including accredited schools. While Negeri Wioi (K2) Elementry School is the school with the lowest score on the standard assessment of education and this school includes accredited school B.

Keywords: Elementry School, National Education Standard, Analysis Description, Southeast Minahasa District

\section{PENDAHULUAN}

Undang-Undang Republik Indonesia nomor 20 tahun 2003 tentang system pendidikan nasional menyatakan bahwa sistem pendidikan nasional harus mampu menjamin pemerataan kesempatan pendidikan peningkatan mutu serta relevansi dan efisiensi manajemen pendidikan untuk menghadapi tantangan sesuai dengan tuntutan perubahan kehidupan lokal, nasional dan global sehingga perlu dilakukan pembaharuan pendidikan secara terencana, terarah dan berkesinambungan. Pendidikan nasional berfungsi untuk mengembangkan kemampuan dan membentuk watak serta peradaban bangsa yang bermartabat dalam rangka mencerdaskan kehidupan bangsa. Sedangkan tujuan pendidikan nasional adalah untuk mengembangkan potensi peserta didik agar menjadi manusia yang beriman dan bertakwa kepada Tuhan Yang Maha Esa, berakhlak mulia, sehat, berilmu, cakap, kreatif, mandiri, dan menjadi warga negara yang demokratis serta bertanggung jawab (Undang-undang nomor 20 tahun 2003 pasal $3)$.

Untuk mengurangi perbedaan mutu pendidikan tersebut, maka telah dibuatkan Peraturan Pemerintah (PP) nomor 19 tahun 2005 tentang Standar Nasional Pendidikan. Standar nasional pendidikan terdiri dari 8 standar, yaitu Standar Kompetensi Lulusan, Standar Isi, Standar Proses, Standar Pendidikan danTenaga Kependidikan, Standar Sarana dan Prasarana, Standar Pengelolaan, Standar Pembiayaan Pendidikan dan Standar Penilaian Pendidikan.

Hatidja (2010), telah melakukan penelitian mengenai mutu pendidikan Sekolah Menengah Atas (SMA) di Kota Manado dengan menggunakan analisis Biplot. Pada penelitian ini tidak menggunakan delapan 8 (delapan) standar nasional pendidikan namun hanya menggunakan beberapa komponen dari 3 (tiga) standar nasional pendidikan, yaitu standar konmpetensi lulusan, standar sarana dan prasarana serta standar proses. Hasil penelitian ini dapat memetakan kelebihan dan kekurangan SMA yang ada di Kota Manado berdasarkan 3 standar tersebut

Kabupaten Minahasa Tenggara yang diresmikan pada tanggal 23 Mei 2007 oleh Menteri Dalam Negeri adalah Kabupaten di Provinsi Sulawesi Utara, yang merupakan pemekaran dari Kabupaten Minahasa Selatan. Kabupaten ini memiliki 42 sekolah TK, 97 SD, 19 SMP dan 15 SMA/SMK. Berdasarkan standar kompetensi lulusan, standar isi dan standar proses, SMP di Kabupaten Minahasa Tenggara dapat dikategorikan: 46\% SMP memiliki mutu baik, dan 54\% SMP memiliki mutu yang tidak baik (Hatidja dan Take, 2012). Namun berdasarkan standar pendidikan dan tenaga kependidikan, standar sarana dan prasarana, standar pengelolaan dan standar pembiayaan pendidikan, SMP di Kabupaten Minahasa Tenggara dapat dikategorikan: $77 \%$ memiliki mutu baik, dan $23 \%$ memiliki mutu yang tidak baik (Daman dan Hatidja, 2012). Kedua hasil di atas dilakukan dengan menggunakan Analisis Biplot.

Purwanto et al. (2015); Sepang et al. (2015), menyatakan bahwa terdapat 2 SMA dan 2 SMK di Kabupaten Minahasa Tenggara mempunyai mutu yang tidak memenuhi Standar Nasional Pendidikan (SNP). Peubah yang digunakan adalah 8 SNP (Standar Kompetensi Lulusan, Standar Isi, Standar Proses, Standar Tenaga Pendidik dan Tenaga Kependidikan, Standar Sarana dan Prasarana, Standar Pengelolaan, Standar Pembiayaan Pendidikan dan Standar Penilaian Pendidikan). Penelitian yang sama juga dilakukan oleh Taarega et al. (2017); 
Rembang et al. (2017) dengan peubah yang digunakan adalah 8 Standar Nasional Pendidikan (SNP) dan masing-masing menggunakan 4 standar yang berbasis Evaluasi Diri Sekolah (EDS), dengan hasil yang didapat yaitu terdapat 4 SMA dan 3 SMK yang belum memenuhi Standar Nasional Pendidikan.

Untuk mengetahui apakah pendidikan dasar di kabupaten Minahasa Tenggara sudah memenuhi standar nasional pendidikan, maka tentu harus dilakukan kajian yang mendalam mengenai Sekolah Dasar.

\section{TINJAUAN PUSTAKA}

\section{Minahasa Tenggara}

Kabupaten Minahasa Tenggara adalah kabupaten baru di Provinsi Sulawesi Utara, Indonesia, dengan ibu kota Ratahan yang merupakan pemekaran dari Kabupaten Minahasa Selatan. Kabupaten ini diresmikan pada tanggal 23 Mei 2007 oleh Menteri Dalam Negeri Ad Interim Widodo AS bersama dengan tiga kabupaten lainnya, yaitu Kabupaten Bolaang Mongondow Utara, Kota Kotamobagu, dan Kabupaten Kepulauan Siau Tagulandang Biaro (Sitaro) (Agust, 2016)

Infrastruktur yang dimiliki, yaitu: 1) lembaga keuangan yang terdiri dari Bank BRI dan BPR dan koperasi; 2) sarana pendidikan yang terdiri dari $42 \mathrm{TK}, 97 \mathrm{SD}$, 19 SMP, 9 SMA, 6 SMK dan 1 MAS; 3) fasilitas kesehatan yang terdiri dari puskesmas, puskesmas pembantu, dan klinik $\mathrm{KB}$, dan tenaga paramedis yang memadai; 4) fasilitas telekomunikasi yang terdiri dari sambungan telepon, wartel, telepon, jaringan TV dan radio; serta 5) fasilitas olahraga

\section{Standar Nasional Pendidikan}

Standar Nasional Pendidikan adalah kriteria minimal tentang sistem pendidikan di seluruh wilayah hukum Negara Kesatuan Republik Indonesia (PP Nomor 19 tahun 2005 pasal 1).

Standar Nasional Pendidikan terdiri dari: 1) Standar Kompetensi Lulusan; 2) Standar Isi; 3) Standar Proses; 4) Standar Pendidik dan Tenaga Kependidikan; 5) Standar Sarana dan Prasarana; 6) Standar Pengelolaan; 7) Standar Pembiayaan
Pendidikan; dan 8) Standar Penilaian Pendidikan(PP Nomor 19 tahun 2005 pasal 2).Standar Nasional Pendidikan berfungsi sebagai dasar dalam perencanaan, pelaksanaan, pengawasan pendidikan dalam rangka mewujudkan pendidikan nasional yang bermutu. Sedangkan tujuan Standar Nasional Pendidikan adalah menjamin mutu pendidikan nasional dalam rangka mencerdaskan kehidupan bangsa dan membentuk watak serta peradaban bangsa yang bermartabat. Standar Nasional Pendidikan disempurnakan secara terencana, terarah, dan berkelanjutan sesuai dengan tuntutan perubahan kehidupan lokal, nasional, dan global (PP Nomor 19 tahun 2005 pasal 3-4).

\section{Standar Kompetensi Lulusan}

Standar kompetensi lulusan adalah kualifikasi kemampuan lulusan yang mencakup sikap, pengetahuan, dan keterampilan. Standar Kompetensi Lulusan untuk satuan pendidikan dasar dan menengah digunakan sebagai pedoman penilaian dalam menentukan kelulusan peserta didik. Standar Kompetensi Lulusan tersebut meliputi: a) standar kompetensi lulusan minimal satuan pendidikan dasar dan menengah; tb) standar kompetensi lulusan minimal kelompok mata pelajaran; dan c) standar kompetensi lulusan minimal mata pelajaran.

Standar kompetensi lulusan pada jenjang pendidikan dasar (SD dan SMP) bertujuan untuk meletakkan dasar kecerdasan, pengetahuan, kepribadian, ahklak mulia, serta keterampilan untuk hidup mandiri dan mengikuti pendidikan lebih lanjut. (Peraturan Menteri Pendidikan Nasional Republik Indonesia Nomor 23 Tahun 2006)

\section{Standar Proses}

Standar proses adalah standar nasional pendidikan yang berkaitan dengan pelaksanaan pembelajaran pada satuan pendidikan untuk mencapai kompetensi lulusan. Standar proses berisi kriteria minimal proses pembelajaran pada satuan pendidikan dasar dan menengah di seluruh wilayah hukum Negara Kesatuan Republik Indonesia. Standar proses ini berlaku untuk jenjang pendidikan dasar dan menengah 
pada jalur formal, baik pada sistem paket maupun pada sistem kredit semester (Peraturan Menteri Pendidikan Nasional (Permendiknas) Nomor 41 tahun 2007).

\section{Standar Pembiayaan Pendidikan}

Standar pembiayaan adalah standar yang mengatur komponen dan besarnya biaya operasi satuan pendidikan yang berlaku selama satu tahun. Pembiayaan pendidikan terdiri atas biaya investasi, biaya operasi, dan biaya personal. Biaya investasi satuan pendidikan sebagaimana dimaksud di atas meliputi biaya penyediaan sarana dan prasarana, pengembangan sumberdaya manusia, dan modal kerja tetap. Biaya personal sebagaimana dimaksud di atas meliputi biaya pendidikan yang harus dikeluarkan oleh peserta didik untuk bisa mengikuti proses pembelajaran secara teratur dan berkelanjutan (Permendiknas nomor 69 tahun 2009)

\section{Standar Penilaian Pendidikan}

Standar penilaian pendidikan adalah standar nasional pendidikan yang berkaitan dengan mekanisme, prosedur, dan instrumen penilaian hasil belajar peserta didik (Permendiknas nomor 20 tahun 2007). Penilaian pendidikan pada jenjang pendidikan dasar dan menengah terdiri atas: 1) Penilaian hasil belajar oleh pendidik; dan 2) Penilaian hasil belajar oleh satuan pendidikan; dan 3) Penilaian hasil belajar oleh Pemerintah.

\section{Analisis Deskripsi}

Beberapa ahli mengatakan bahwa analisis multivariat adalah hubungan antara atau diantara lebih dari dua variabel atau peubah. Tujuan analisis multivariat adalah mengukur, menerangkan dan memprediksi tingkat relasi di antara variat-variat. Jadi, karakter multivariat tidak sekedar berada pada jumlah variabel atau observasi yang dilibatkan dalam analisis tetapi juga pada kombinasi antar variat. Variat adalah kombinasi linier variabel-variabel yang memiliki bobot yang penentuannya dilakukan secara empiris (Simamora, 2005).

Analisis multivariat lebih banyak menekankan pada metode-metode statistik yang bersifat menggambarkan dan menganalisis data-data multivariat. Cara penggambaran data tersebut sebagian besar disajikan dalam bentuk gambar atau grafik. Dengan demikian analisis multivariat sebenarnya merupakan bagian dari statistika deskripsi (Johnson and Wichern, 2005)

Menurut Hatidja dan Mongi (2009), statistika Deskripsi adalah bidang statistika yang membicarakan cara mengumpulkan, menyederhanakan dan menyajikan data sehingga bisa memberikan informasi. Para ahli statistika biasanya bekerja dengan data numerik berupa skala pengukuran data dan dalam dua pengukuran data yaitu ukuran pemusatan dan ukuran penyebaran.

\section{METODOLOGI PENELITIAN}

\section{Waktu dan Tempat Penelitian}

Penelitian ini dilakukan pada bulan September tahun 2017 dan tempat penelitian dilakukan di Kabupaten Minahasa Tenggara.

\section{Sumber Data}

Data yang digunakan dalam penelitian ini berasal dari data primer. Data primer diambil di Sekolah Dasar (SD) di Kabupaten Minahasa Tenggara yang berisi Standar Nasional Pendidikan. Data-data dikumpul melalui kuisioner di setiap sekolah berdasarkan wawancara yang dilakukan terhadap Kepala Sekolah dan Guru.

\section{Objek Penelitian}

Populasi yang dijadikan objek penelitian adalah Sekolah Dasar di Kabupaten Minahasa Tenggara sebanyak 30 sampel dari 97 populasi Sekolah Dasar (Tabel 1).

Penelitian ini menggunakan data hasil survei dengan menggunakan teknik pengambilan sampel yakni Purposive Random Sampling yang digunakan untuk menentukan kecamatan yang akan dijadikan sampel, kemudian menggunakan Simple Random Sampling untuk menentukan sekolah-sekolah yang akan dijadikan sampel. Besarnya sampel ditentukan dengan rumus sebagai berikut:

$$
n=\frac{N}{N \cdot d^{2}+1}
$$


Dimana: $\mathrm{n}=$ jumlah sampel

$\mathrm{N}=$ jumlah populasi

$\mathrm{d}^{2}=$ presisi yang diterapkan $(3 \%)$

(Ridwan dan Akdon, 2005)

$N=97$

$\mathrm{d}^{2}=0.03$

$$
n=\frac{97}{97(0.03)+1}=24.808
$$

Besarnya sampel yang diperoleh dengan menggunakan persamaan (1) adalah 25, namun untuk lebih akurat diambil sebanyak $30 \mathrm{SD}$.

Tabel 1. Nama-nama Sekolah Dasar yang menjadi objek penelitian

\begin{tabular}{|c|c|c|}
\hline No & Nama Sekolah & Simbol \\
\hline 1 & SDN 2 RATAHAN & K1 \\
\hline 2 & SDN WIOI & K2 \\
\hline 3 & SD GMIM RATAHAN & K3 \\
\hline 4 & $\begin{array}{l}\text { SD INPRES } \\
\text { TOSURAYA }\end{array}$ & K4 \\
\hline 5 & SD GMIM RASI & K5 \\
\hline 6 & SDN 1 LIWUTUNG & K6 \\
\hline 7 & SDN 2 LIWUTUNG & K7 \\
\hline 8 & SDN 3 LIWUTUNG & K8 \\
\hline 9 & SD INPRES PANGU & K9 \\
\hline 10 & SD INPRES LIWUTUNG & K10 \\
\hline 11 & SDN 1 MOLOMPAR & K11 \\
\hline 12 & SDN MUNDUNG & K12 \\
\hline 13 & SD GMIM KUYANGA & K13 \\
\hline 14 & SDN 2 TOMBATU & K14 \\
\hline 15 & SD GP KALI & K15 \\
\hline 16 & SD GMIM LOBU & K16 \\
\hline 17 & SDN KECIL BANGA & K17 \\
\hline 18 & SD GMIM BUNAG & K18 \\
\hline 19 & SDN MAULIT & K19 \\
\hline 20 & $\begin{array}{l}\text { SDN INPRES } \\
\text { MOLOMPAR }\end{array}$ & K20 \\
\hline 21 & SD GMIM WATULINEY & K21 \\
\hline 22 & SDN TABABO & K22 \\
\hline 23 & SDN 1 BELANG & K23 \\
\hline 24 & SDN 1 TOMBATU & K24 \\
\hline 25 & $\begin{array}{l}\text { SD GMIM } \\
\text { RANOKETANG }\end{array}$ & K25 \\
\hline 26 & SDN 1 TOUMDANOW & K26 \\
\hline 27 & SD GMIM 1 SILIAN & K27 \\
\hline 28 & SDN SILIAN RAYA & K28 \\
\hline 29 & SD INPRES KALI & K29 \\
\hline 30 & SD GMIM TAMBELNG & K30 \\
\hline
\end{tabular}

\section{Peubah atau Variabel Penelitian}

Peubah-peubah yang diamati adalah peubah standar nasional pendidikan yang terdiri dari Standar Kompetensi Lulusan, Standar Proses, Standar Pembiayaan Pendidikan dan Standar Penilaian Pendidikan: Peubah-peubah yang diamati disajikan pada Tabel 2-5.

Tabel 2. Peubah Standar Kompetensi Lulusan (X1)

\begin{tabular}{|c|l|}
\hline Kode & \multicolumn{1}{|c|}{ Nama Peubah } \\
\hline X11 & $\begin{array}{l}\text { Nilai rata-rata mata pelajaran } \\
\text { agama siswa kelas 6 }\end{array}$ \\
\hline X12 & $\begin{array}{l}\text { Nilai rata-rata mata pelajaran } \\
\text { Pendidikan Kewarganegaraan } \\
\text { kelas 6 }\end{array}$ \\
\hline X13 & $\begin{array}{l}\text { Nilai rata-rata mata pelajaran } \\
\text { Bahasa Indonesia kelas 6 }\end{array}$ \\
\hline X14 & $\begin{array}{l}\text { Nilai rata-rata mata pelajaran } \\
\text { Matematika kelas 6 }\end{array}$ \\
\hline X15 & $\begin{array}{l}\text { Nilai rata-rata mata pelajaran IPA } \\
\text { kelas 6 }\end{array}$ \\
\hline X16 & $\begin{array}{l}\text { Nilai rata-rata mata pelajaran IPS } \\
\text { kelas 6 }\end{array}$ \\
\hline X17 & $\begin{array}{l}\text { Nilai rata-rata mata pelajaran Seni } \\
\text { Budaya dan keterampilan kelas 6 }\end{array}$ \\
\hline X18 & $\begin{array}{l}\text { Nilai rata-rata mata pelajaran } \\
\text { pendidikan jasmani dan olahraga } \\
\text { kelas 6 }\end{array}$ \\
\hline X19 & $\begin{array}{l}\text { Nilai rata-rata mata pelajaran } \\
\text { Muatan Lokal kelas 6 }\end{array}$ \\
\hline X110 & $\begin{array}{l}\text { Nilai rata-rata Ujian Nasional } \\
\text { (UAN) lulusan }\end{array}$ \\
\hline X111 & Nilai rata-rata siswa kelas 4 \\
\hline X112 & Nilai Rata-rata siswa kelas 5 \\
\hline X113 & Nilai Rata-rata siswa kelas 6 \\
\hline
\end{tabular}

Tabel 3. Peubah Standar Proses (X2)

\begin{tabular}{|l|l|}
\hline Kode & \multicolumn{1}{|c|}{ Nama Peubah } \\
\hline & Silabus \\
\hline & $\begin{array}{l}\text { Rencana pelaksanaan } \\
\text { pembelajaran }\end{array}$ \\
\hline X21 & Jumlah siswa kelas 4 \\
\hline X22 & Jumlah siswa kelas 5 \\
\hline X23 & Jumlah siswa Kelas 6 \\
\hline X24 & Jumlah ruang dengan siswa $\leq 32$ \\
\hline X25 & Jumlah ruang dengan siswa $>32$ \\
\hline
\end{tabular}


Tabel 4. Peubah Standar Pembiayaan Pendidikan (X3)

\begin{tabular}{|c|l|}
\hline Kode & \multicolumn{1}{|c|}{ Nama Peubah } \\
\hline X31 & Jumlah siswa kelas 1-6 \\
\hline X32 & $\begin{array}{l}\text { Biaya untuk bahan atau peralatan } \\
\text { pendidikan habis pakai } \\
\text { (ATM/ATK) }\end{array}$ \\
\hline X33 & $\begin{array}{l}\text { Biaya operasi pendidikan tak } \\
\text { langsung (air, telepon, } \\
\text { pemeliharaan sarana dan } \\
\text { prasarana, uang lembur, } \\
\text { transportasi) }\end{array}$ \\
\hline
\end{tabular}

Tabel 5. Peubah Standar Penilaian Pendidikan (X4)

\begin{tabular}{|c|l|}
\hline Kode & \multicolumn{1}{|c|}{ Nama Peubah } \\
\hline X41 & $\begin{array}{l}\text { Ketersediaan prosedur kriteria } \\
\text { penilaian dapat diakses : }(\%)\end{array}$ \\
\hline X42 & $\begin{array}{l}\text { Petunjuk pelaksanaan yang } \\
\text { tersedia dan digunakan di Sekolah } \\
\text { meliputi : (pedoman penelitian, } \\
\text { kriteria ketuntasan dan petunjuk } \\
\text { tentang nilai KKM) }\end{array}$ \\
\hline
\end{tabular}

\section{Metode Analisis}

Metode analisis yang dilakukan dalam penelitian ini yaitu analisis deskripsi terhadap data asal yakni Standar Nasional Pendidikan. Hal ini dilakukan untuk mengetahui gambaran data secara umum, dalam hal ini 4 indikator Standar Nasional Pendidikan sebagai variabel/peubah dan Sekolah Dasar (SD) sebagai objek pengamatan. Analisis Deskripsi dilakukan dengan menggunakan perangkat lunak Excel.

\section{HASIL DAN PEMAHASAN}

\section{Akreditasi Sekolah}

Tabel 6. Jumlah dan Persentasi Akreditasi Sekolah

\begin{tabular}{|c|c|c|}
\hline Akreditasi & $\begin{array}{c}\text { Jumlah } \\
\text { SD }\end{array}$ & $\begin{array}{c}\text { Presentasi } \\
(\mathbf{\%})\end{array}$ \\
\hline A & 9 & 30 \\
\hline B & 9 & 30 \\
\hline C & 1 & 3,33 \\
\hline $\begin{array}{c}\text { Belum } \\
\text { Terakreditasi }\end{array}$ & 11 & 36,67 \\
\hline Total & 30 & 100 \\
\hline
\end{tabular}

Dapat dilihat pada tabel 7 bahwa dari grade akreditasi terdapat $9 \quad(30 \%)$ sekolah memiliki akreditasi A yaitu SD Negeri 2 Ratahan (K1), SD GMIM Ratahan (K3), SD Negeri 1 Liwutung (K6), SD Negeri 2 Liwutung (K7), SD Negeri 3 Liwutung (K8), SD Negeri Mundung (K12), SD GP Kali (K15) SD Negeri 1 Tombatu (K24) dan SD Inpres Kali (K29), 9 (30\%) sekolah memiliki akreditasi B yaitu SD Negeri Wioi (K2), SD Inpres Tosuraya (K4), SD GMIM Rasi (K5), SD Inpres Pangu (K9), SD Inpres Liwutung (K10) SD Negeri 1 Molompar (K11) SD Negeri Tababo (K22), SD GMIM Ranoketang (K25) dan SD GMIM Tambelang (K30), 1 (3,33\%) sekolah memiliki akreditasi $\mathrm{C}$ yaitu SD Negeri 2 Tombatu (K14) dan $11(36,67 \%)$ sekolah yang belum terakreditasi yaitu SD GMIM Kuyanga (K13), SD GMIM Lobu (K16), SD Negeri Kecil Banga (K17), SD GMIM Bunag (K18), SD Negeri Maulit (K19), SD Negeri Inpres Molompar (K20), SD GMIM Watuliney (K21), SD Negeri 1 Belang (K23), SD Negeri 1 Toundanow (K26), SD GMIM 1 Silian (K27) dan SD Negeri Silian Raya (K28).

\section{Deskripsi Peubah Standar Kompetensi Lulusan (X1)}

Pada peubah standar kompetensi lulusan, diambil nilai rata-rata setiap mata pelajaran yaitu mata pelajaran Agama, Pendidikan Kewarganegaraan, Bahasa Indonesia, Matematikan, IPA, IPS, Seni Budaya dan Keterampilan, Pendidikan Jasmani dan Olahraga dan Muatan Lokal. Nilai rata-rata masing-masing mata pelajaran diambil dari nilai Raport siswa kelas 6 .

\section{Nilai Rata-rata Semua Mata Pelajaran}

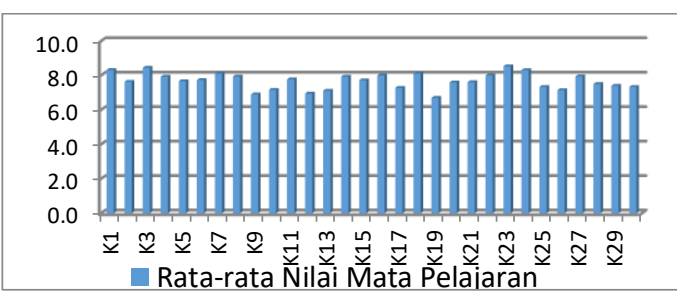

Gambar 1. Nilai Rata-rata semua Mata Pelajaran

Gambar 1 menunjukan bahwa dari nilai rata-rata semua mata pelajaran $\mathrm{SD}$ Negeri 1 Belang (K23) memiliki nilai paling tinggi yaitu 8,5, kemudian di diurutan kedua 
SD GMIM Ratahan (K3) dengan nilai 8,4. Sedangkan sekolah yang memiliki nilai paling rendah yaitu SD Negeri Maulit (K19) dengan nilai 6,7 .

\section{Nilai Rata-Rata Ujian Nasional (UAN) Lulusan (X110)}

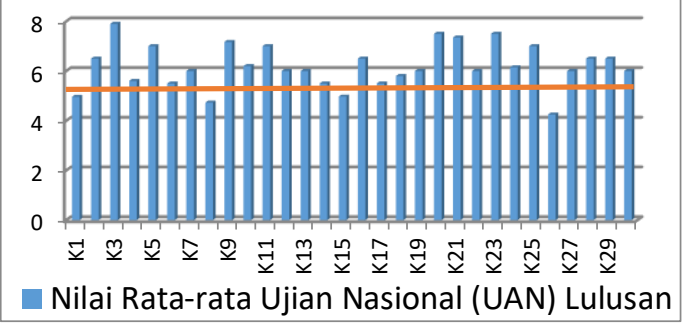

Gambar 2. Nilai Rata-rata Ujian Nasional (UAN) Lulusan

Pada grafik dapat dilihat Sekolah Dasar (SD) yang memiliki nilai rata-rata ujian nasional lulusan tertinggi dimiliki oleh SD GMIM Ratahan (K3) dengan nilai 7,9, SD Negeri Inpres Molompar (K20) dan SD Negeri Tababo berada pada urutan kedua tertinggi dengan nilai rata-rata yang dimiliki yaitu 7,5, diikuti SD GMIM Watuliney (K21) dengan nilai 7.35 dan SD Inpres Pangu (K9) dengan nilai 7,17. Sedangkan yang memiliki nilai terendah yaitu SD Negeri 1 Toundanow (K26), SD Negeri 3 Liwutung (K8), SD Negeri 2 Ratahan (K1) dan SD GMIM Watuliney (K21) dengan nilai masing-masing 4,25 4,73, 4,96 dan 4,97, keempat sekolah tersebut merupakan sekolah yang tidak mencapai nilai standar ujian nasional dengan nilai standar ujian nasional yaitu 5,5 (Gambar 2).

\section{Nilai Rata-Rata Siswa Kelas 4 (X111)}

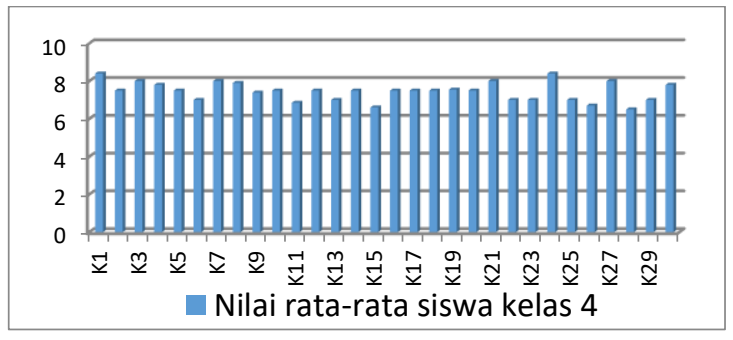

Gambar 3. Nilai Rata-rata Siswa Kelas 4

SD Negeri 2 Ratahan (K1) dan SD Negeri 1 Tombatu (K24) memiliki nilai ratarata kelas 4 paling tinggi dengan nilai ratarata 8.4, sedangkan SD Negeri Silian Raya
(K28) berada pada posisi paling rendah dengan nilai rata-rata kelas 4 yang dimiliki yaitu 6.5 begitu juga dengan SD GP Kali (K15) dan SD Negeri 1 Toundanow dengan nilai yang dimiliki masing-masing hanya 6.6 dan 6.7 (Gambar 3).

Nilai Rata-Rata Siswa Kelas 5 (X112)

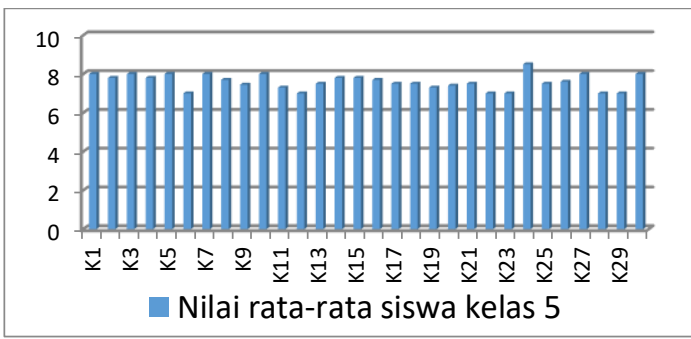

Gambar 4. Nilai Rata-rata Siswa Kelas

Gambar 4 menunjukkan bahwa nilai rata-rata siswa kelas 5 paling tinggi dimiliki oleh SD Negeri 1 Tombatu (K24) dengan nilai rata-rata 8,5. Sedangkan SD Negeri 1 Liwutung (K6), SD Negeri Mundung, SD Negeri Tababo(K22), SD Negeri 1 Belang (K23), SD Negeri 1 Silian Raya (K28) dan SD Inpres Kali (K29) adalah sekolah yang memiliki nilai paling rendah, dengan nilai rata-rata 7.

Nilai Rata-Rata Siswa Kelas 6 (X113)

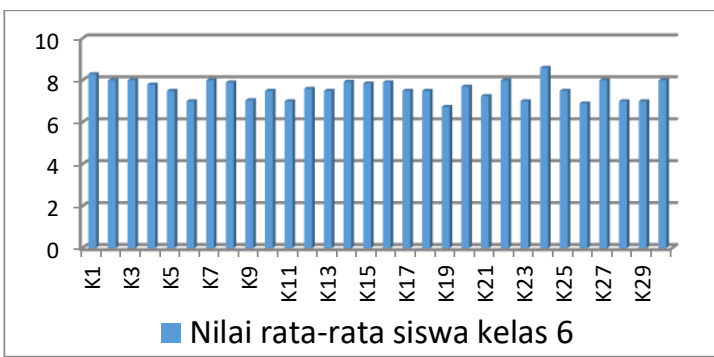

Gambar 5. Nilai Rata-rata Siswa Kelas 6

Pada Grafik terlihat bahwa, sekolah yang memiliki nilai rata-rata kelas 6 paling rendah yaitu SD Negeri Maulit (K19) dengan nilai rata-rata hanya 6,73. SD Negeri 2 Ratahan (K1) berada pada urutan tertinggi kedua dengan nilai rata-rata yang dimiliki yaitu 8,3 dan sekolah yang memiliki nilai rata-rata paling tinggi yaitu SD Negeri 1 Tombatu (K24) degan nilai yang dimiliki yaitu 8,6 (Gambar 5). 


\section{Deskripsi Peubah Standar Proses (X2)}

Pada peubah standar proses yang berkaitan dengan perencanaan proses pembelajaran yang meliputi Silabus dan Rencana Pelaksanaan Pembelajaran (RPP) sudah diterapkan oleh masing-masing sekolah.

\section{Jumlah Siswa Kelas 4 (X21)}

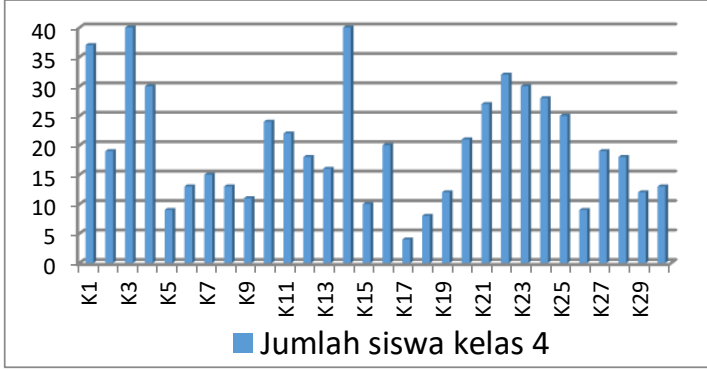

Gambar 6. Jumlah Siswa Kelas 4

Siswa kelas 4 yang memiliki jumlah terbanyak yang dapat dilihat pada grafik diantaranya SD GMIM Ratahan (K3) dan SD Negeri 2 Tombatu (K14) dengan jumlah siswa yang dimiliki sebanyak 40, kemudian SD Negeri 2 Ratahan (K1) di urutan kedua terbanyak dengan jumlah siswa yang dimiliki yaitu 37 siswa. Sedangkan SD Negeri Kecil Banga hanya memiliki 4 jumlah siswa kelas 4 dengan kata lain SD Negeri Kecil Banga merupakan sekolah yang memiliki jumlah siswa kelas 4 paling sedikit (Gambar 6).

\section{Jumlah Siswa Kelas 5 (X22)}

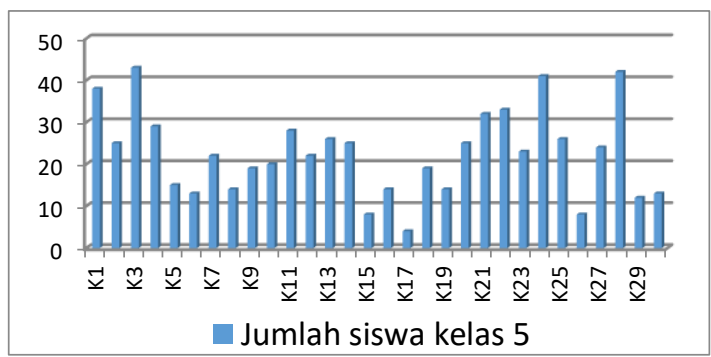

Gambar 7. Jumlah Siswa Kelas 5

Jumlah siswa kelas 5 paling sedikit pada Gambar 7 adalah SD Negeri Kecil Banga (K17) yang hanya memiliki 4 siswa kelas 5, SD GP Kali (K15) dan SD Negeri 1 Toundanow (K26) juga memiliki jumlah siswa kelas 5 sedikit yaitu 8 siswa. Sekolah yang memiliki jumlah siswa kelas 5 paling banyak antara lain SD GMIM Ratahan (K3) 43 siswa, SD Negeri Silian Raya (K28) 42 siswa dan SD Negeri 1 Tombatu (K24) 41 siswa.

\section{Jumlah Siswa Kelas 6 (X23)}

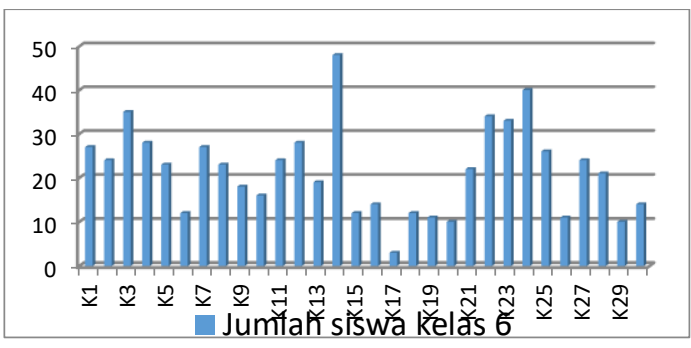

Gambar 8. Jumlah Siswa Kelas 6

SD Negeri 2 Tombatu (K14) berada pada urutan pertama sekolah yang memiliki jumlah siswa kelas 6 yang paling banyak yaitu 48 siswa, diurutan kedua yaitu SD Negeri 1 Tombatu (K24) dengan jumlah siswa kelas 6 sebanyak 40 siswa. SD Negeri kecil Banga (K17) hanya memiliki jumlah siswa kelas 6 sebanyak 3 siswa, sehingga dapat dikatakan bahwa SD Negeri kecil Banga (K17) merupakan sekolah yang memiliki siswa kelas 6 paling sedikit dari antara sekolah-sekolah yang lain (Gambar 8).

\section{Jumlah Ruangan dengan Siswa $\leq 32$ (X24)}

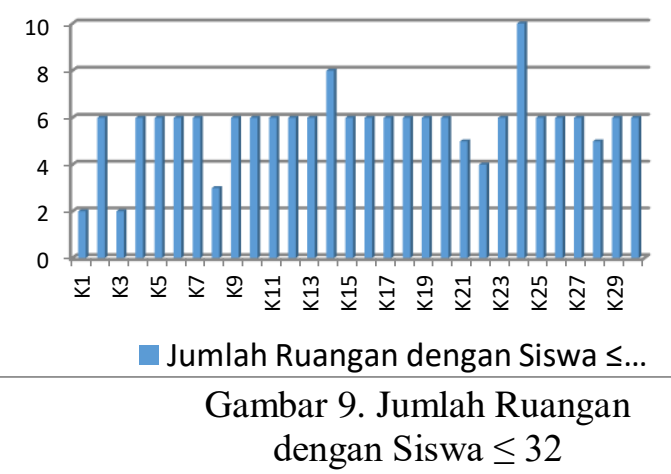

Gambar 9 menunjukan bahwa sekolah yang memiliki jumlah ruangan dengan siswa $\leq 32$ yaitu SD Negeri 1 Tombatu (K24) sebanyak 10 ruangan dan SD Negeri 2 Tombatu sebanyak 8 ruangan. Untuk sekolah yang memiliki ruangan dengan siswa $\leq 32$ paling sedikit yaitu SD Negeri 2 Ratahan(K1) dan SD GMIM Ratahan(K3) memiliki 2 ruangan, SD Negeri 
3 Liwutung (K8) 3 ruangan, SD Negeri Tababo (K22) 4 ruangan, SD GMIM Watuliney (K21) dan SD Negeri Silian Raya (K28) memiliki 5 ruangan dan sisanya memiliki ruangan dengan siswa $\leq 32$ masing-masing 6 ruangan.

\section{Jumlah Ruangan dengan Siswa $\geq 32$ (X25)}

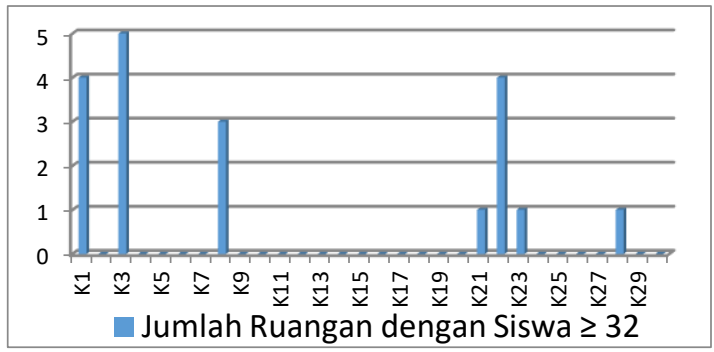

Gambar 10. Jumlah Ruangan dengan Siswa $\geq 32$

Dapat dilihat pada gambar 10, sebagian besar Sekolah Dasar tidak memiliki ruangan dengan siswa $\geq 32$ yaitu sebanyak 23 SD dan 7 SD lainnya memiliki ruangan dengan siswa $\geq 32$ antara lain SD GMIM Watuliney (K21), SD Negeri 1 Belang (K23) dan SD Negeri Silian Raya (K28) masingmasing memiliki 1 ruangan, SD Negeri 3 Liwutung memiliki 3 ruangan, SD Negeri 2 Ratahan (K1) dan SD Negeri Tababo (K22) masing-masing 4 ruangan dan yang memiliki ruangan dengan siswa $\geq 32$ paling banyak yaitu SD GMIM Ratahan sebanyak 5 ruangan.

\section{KESIMPULAN DAN SARAN}

\section{Kesimpulan}

SD GMIM Ratahan (K3) adalah sekolah yang memiliki nilai paling tinggi pada tiga Standar Nasional Pendidikan yaitu standar kompetensi lulusan, standar proses dan standar pembiayaan pendidikan, sekolah ini termasuk sekolah yang sudah terakreditasi A. Sedangkan sekolah yang memiliki nilai paling rendah adalah SD GMIM Kuyanga (K13) untuk standar kompetensi lulusan dan SD Negeri Kecil Banga (K17) untuk standar proses dan standar pembiayaan pendidikan, kedua sekolah tersebut termasuk sekolah yang belum terakreditasi. SD Negeri 1 Tombatu
(K24) adalah sekolah yang memiliki nilai paling tinggi untuk standar penilaian pendidikan dan sekolah ini termasuk sekolah yang sudah terakreditasi. Sedangkan SD Negeri Wioi (K2) adalah sekolah dengan nilai paling rendah pada standar penilaian pendidikan dan sekolah ini termasuk sekolah yang sudah terakreditasi B.

\section{Saran}

Dari keempat Standar Nasional Pendidikan yang digunakan dalam penelitian ini setiap sekolah memiliki kekurangannya masing-masing. Sebaiknya guru yang mengajar harus sesuai dengan mata pelajaran, kemudian harus ada dorongan dari kepala sekolah bagi guru-guru agar melanjutkan studi ke perguruan tinggi bagi yang belum kuliah dan untuk siswa-siswa selain belajar di sekolah sebaiknya mengikuti les pribadi.

\section{DAFTAR PUSTAKA}

Agust, J. 2016. MITRA (Kabupaten Minahasa Tenggara) Sulawesi Utara.

Http://www.skyscrapercity.com/sho wthread.php?t=1911547

[6 Desember 2017].

Daman, R. dan Dj. Hatidja. 2012. Pemetaan SMP-SMP di Kab. Minahasa Tenggara Berdasarkan Standar Pendidikan dan Tenaga Kependidikan, Standar Sarana dan Prasarana, Standar Pengelolaan, dan Standar Pebiayaan Menggunakan Analisis Biplot. Jurnal De Cartesian 1(1):34-35.

Johnson, R. A and D. Wichern. 2005. Applied Multivariate Statistical Analysis. Fifth Edition. Prentice Hall Inc., USA.

Hatidja, D. 2010. Analisis Biplot Terhadap Mutu Pendidikan SMA-SMA di Kota Manado. Jurnal Ilmiah Sains, 10(1).

Hatidja, D. dan R. Take. 2012. Pemetaan SMP-SMP di Kab. Minahasa Tenggara Berdasar-kan Standar Kompetensi Lulusan, Standar Isi dan Standar Proses. Prosiding Seminar Nasional Matematika XVI, Bandung 3-6 Juli 2012. 
Hatidja, D. dan C. Mongi. 2009. Metode Statistika I. Bahan Ajar. FMIPA Unsrat, Manado.

Peraturan Menteri Pendidikan Nasional Republik Indonesia Nomor 23 Tahun 2006 tentang Standar Kompetensi Lulusan (SKL).

Peraturan Menteri Pendidikan Nasional Republik Indonesia Nomor 41 tahun 2007 tentang Standar Proses.

Peraturan Menteri Pendidikan Nasional Republik Indonesia Nomor 69 Tahun 2009 tentang Standar Pembiayaan Pendidikan.

Peraturan Menteri Pendidikan Nasional Republik Indonesia Nomor 20 Tahun 2007 tentang Standar Penilaian Pendidikan.

Peraturan Pemerintah Republik Indonesia Nomor 19 Tahun 2005 tentang Standar Nasional Pendidikan.

Purwanto, Ch., D. Hatidja, dan M. Paendong. 2015. Pemetaan SMA/SMK Di Kabupaten Minahasa Tenggara Berdasarkan Empat Indikator Standar Nasional Pendidikan Dengan Menggunakan Analisis Biplot. Jurnal De Cartesian 4(1):41.

Rembang, P., D. Hatidja dan H. Komalig. 2017. Deskripsi SMA/SMK Di Kabupaten Minahasa Tenggara Berdasarkan Indikator Standar Nasional Pendidikan Berbasis Evaluasi Diri Sekolah (Standar Sarana dan Prasarana, Standar Pengelolaan, Standar Pembiayaan Pendidikan dan Standar Penilaian Pendidikan). Jurnal Ilmiah Sains 17(2):124.
Sepang, M.Z., D. Hatidja dan Y. Langi. 2015. Pemetaan SMA dan SMK Berdasarkan Standar Kompetensi Lulusan, Proses, Pembiayaan Pendidikan, dan Penilaian Pendidikan Menggunakan Analisis Biplot di Kabupaten Minahasa Tenggara. Jurnal De Cartesian 4(1):217.

Simamora, B. 2005. Analisis Multivariat Pemasaran. PT Gramedia Pustaka Utama, Jakarta.

Ridwan dan Akdon. 2005. Rumus dan Data dalam Aplikasi Statistika. Alfabeta, Bandung.

Taarega, S.K., D. Hatidja dan M. Paendong. 2016. Deskripsi SMA dan SMK di Kabupaten Minahasa Tenggara Berdasarkan Standar Nasional Pendidikan Berbasisi Evaluasi Diri Sekolah (Standar Kompetensi Lulusan, Standar Isi, Standar Proses dan Tenaga Kependidikan). Jurnal Ilmiah Sains 16(2):67.

Undang-Undang Republik Indonesia Nomor 20 Tahun 2003 Tentang Sistem Pendidika Nasional. 